\title{
Presence and distribution of serotonin immunoreactivity in the cyprids of the barnacle Balanus amphitrite
}

\author{
L. Gallus, ${ }^{1,4}$ P. Ramoino, ${ }^{1}$ M. Faimali, ${ }^{2}$ V. Piazza, ${ }^{2}$ G. Maura, ${ }^{3}$ M. Marcoli, ${ }^{3}$ S. Ferrando, ${ }^{4}$ L. Girosi, ${ }^{4}$ \\ G. Tagliafierro ${ }^{4}$ \\ ${ }^{1}$ Dipartimento per lo studio del Territorio e delle sue Risorse, Università di Genova; ${ }^{2}$ Istituto di Scienze \\ Marine, CNR Genova; ${ }^{3}$ Dipartimento di Medicina Sperimentale, Sezione di Farmacologia e Tossicologia, \\ Università di Genova; ${ }^{4}$ Dipartimento di Biologia, Università di Genova, Italy
}

(C)2005, European Journal of Histochemistry

In this work, the presence and distribution of serotonin in the cyprid of the barnacle Balanus amphitrite were investigated by immunohistochemical methods. Serotonin-like immunoreactive neuronal cell bodies were detected in the central nervous system only. Various clusters of immunoreactive neuronal cell bodies are distributed in the brain (protocerebrum, deutocerebrum, optical lobes), and at least, four pairs of neuronal cell bodies were detected in the centrally positioned neuropil of the posterior ganglion. Rich plexuses of immunoreactive nerve fibers in the neuropil area were also observed. Furthermore, bundles of strongly immunoreactive nerve fibers surrounding the gut wall were localized, and immunoreactive nerve terminals in the antennules and compound eyes were observed. These data demonstrate the presence of a serotonin-like immunoreactive substance in the barnacle cyprids; furthermore, its immunolocalization in the cephalic nerve terminals allows us to postulate the involvement of this bioactive molecule in substrate recognition during the settlement process.

Key words: barnacle cyprid, nervous system, serotonin, immunohistochemistry.

Correspondence: Dr. Lorenzo Gallus,

Università di Genova, Dipartimento di Biologia,

Viale Benedetto XV, 5, 16132 Genova, Italy

Tel: +39.010.3537015.

Fax: +39.010.3538047

E-mail: gallus@unige.it

Paper accepted on September 16, 2005

European Journal of Histochemistry

2005; vol. 49 issue 4 (Oct-Dec): 341-348
S erotonin (5-hydroxytryptamine, 5-HT) is considered to be one of the most ancient neurotransmitters, largely distributed both in vertebrates and invertebrates (Fujii and Takeda, 1988). Besides being a neurotransmitter it also plays important roles in non-neural processes, from cell proliferation and apoptosis (Azmitia, 2001) to neural cell migration (Moiseiwitsch and Lauder, 1995). Serotonin was the first neuroactive substance immunohistochemically detected in the nervous system of crustaceans (Beltz and Kravitz, 1983 ) and it has been mapped in numerous arthropod species, both in adult and in larval specimens (Battelle et al., 1999; Harzsch and Waloszek, 2000). It is believed that in decapods, serotonin may act in both the central and peripheral nervous systems, controlling the threat postures and escape mechanisms that characterize agonistic encounters (Harris-Warrick and Kravitz 1984; Yeh et al., 1997), as well the rate of heart beat (Listerman et al., 2000).

Serotonin-like immunoreactivity has been also detected in the adult barnacle central nervous system (Tagliafierro et al., 1989; Callaway and Stuart, 1999); although experimental data are not yet available in literature, it has been suggested that serotonin may play a role in barnacle limb motility (Callaway and Stuart, 1999).

Barnacles are cirripedian crustaceans, with strongly reduced head and abdomen. For their sessile adult condition, and their ability to adhere to any kind of natural or artificial substrate, they are considered to be among the most important constituents of animal fouling (Christie and Dalley, 1987). Thoracican barnacles generally have six naupliar and one cyprid planktonic larval stages (Newman, 1987). The cyprid is specialized for settlement, and metamorphosis (Yule and Walker, 1987): it initiates an exploratory period, passing 
through a series of reversible bindings to the substrate, adheres irreversibly to the selected structure by the cement gland secretion (Crisp, 1984; Strathman, 1987; Walker et al., 1987), and finally metamorphoses into a sessile juvenile organism (Walker, 1971; Okano et al., 1996). The neurobiology of the barnacle is well known, its central nervous system (CNS) is constituted by a simple bilobed structure of the supraesophageal ganglion and by a ventral ganglionic mass referred as thoracic ganglion or subesophageal ganglion; the two structures are joined by circumesophageal connectives (Gwilliam and Cole 1979; Gwilliam, 1987). At present, only few neurotransmitters or bioactive molecules have been immunodetected in the CNS of adult barnacles: histamine and serotonin in Semibalanus cariosus, Balanus nubilus and Pollicipes polymerus (Callaway and Stuart, 1999), pigment dispersing hormone (PDH) and crustacean cardioactive peptide (CCAP) in Balanus balanus, Balanus perforatus and Chirona (balanus) hameri (Webster, 1998), serotonin and FMRFamide in Balanus amphitrite (Tagliafierro et al., 1989; Gallus et al., 2001). Also the neurobiology of the CNS of the barnacle's larval stages has been recently studied; its nervous system is constituted by two thousand neurons only, well organized for the coordination of the compound and median eyes, the antennules and the setae, which are fundamental for substrate recognition and adhesion (Walker, 1992; Harrison and Sandeman, 1999).

The presence of a few signal molecules was suggested by experimental tests or immunohistochemical methods: histamine in $B$. amphitrite (Stuart et al., 2002) and acetylcholinesterase in $B$. amphitrite (Faimali et al., 2003). Furthermore, in the cyprid of $B$. amphitrite, serotonin and dopamine were detected by HPLC (Yamamoto et al., 1999), and an aromatic L-amino acid decarboxylase (AADC) gene, the product of which catalyzes, respectively, the synthesis of serotonin and dopamine from L-5-hydroxytryptophane and L3,4-dihydroxyphenylalanine, was furthermore characterized (Okazaki and Shizuri, 2001). The role of serotonin in settlement and metamorphosis was indicated by numerous settlement tests (Kon-ya et al., 1995; Yamamoto et al., 1996; Yamamoto et al., 1999). Nevertheless, no data are until now available about the distribution of serotonin-like immunoreactivity in the barnacle larvae.

The purpose of this paper was to study the pres- ence, distribution and localization of serotonin-like substances in the $B$. amphitrite cyprids by immunohistochemical methods. The distribution of cyprid serotonergic neurons will be compared to that of other crustacean species as recently reviewed by Harzsch and Waloszek (2000).

\section{Materials and Methods}

\section{Biological material}

Cyprids were obtained from laboratory cultures of brood stock of Balanus amphitrite amphitrite Darwin (Rittschof et al., 1992). Twenty to thirty adult barnacles were reared in $700 \mathrm{ml}$ beakers containing aerated filtered sea water at $28 \pm 1^{\circ} \mathrm{C}$, with a 16h:8h light:dark (L:D) cycle. They were fed every two days with 50-100 ml Artemia salina sp. at the concentration 20 larvae $\mathrm{mL}^{-1}$, and $200-400 \mathrm{~mL}$ of Tetraselmis suecica at the concentration $2 \times 10^{6}$ cells $\times \mathrm{mL}^{-1}$. The water was changed three times per week and barnacles were periodically rinsed with fresh water to remove epibionts and other debris. Adult barnacles, reared under such conditions, produce nauplii throughout the year. Nauplii were collected and reared in $500 \mathrm{ml}$ beakers on Tetraselmis suecica $\left(5 \times 10^{5}\right.$ cells $\left.\mathrm{mL}^{-1}\right)$ in $0.22 \mu \mathrm{m}$ filtered seawater, at $28 \pm 1^{\circ} \mathrm{C}$ with a $16 \mathrm{~h}: 8 \mathrm{~h} \mathrm{~L}: \mathrm{D}$ cycle, until they reached the cyprid stage.

\section{Histological and immunohistochemical methods}

About 200 zero to five day-old cyprids were used. They were anesthetized with 3-aminobenzoic acid ethyl methanesulfonate salt (Sigma, USA) (1:1000 in sea water) and the cyprid body was fixed in $4 \%$ paraformaldehyde in $0.1 \mathrm{M}$ phosphate buffer saline, $\mathrm{pH} 7.4$ (PBS). In order to enhance neuronal cell body immunoreactivity (as suggested by Yamamoto et al., 1998), further 100 cyprids were treated with colchicine (Sigma, USA) $(0.03 \%$ in sea water) for 30 minutes before anesthesia and fixation. Subsequently the cyprids were PBS rinsed, dehydrated, and embedded in paraplast (Bioptica, Italy). Dewaxed transversal and longitudinal serial sections ( $5 \mu$ thick) were pre-incubated with normal goat serum (1:50), immunohistochemically treated overnight at room temperature with a rabbit polyclonal anti-human serotonin antiserum (prediluted, Biomeda, USA), PBS rinsed and alternatively treated, for two hours at room temperature, with a goat fluorescein isothiocyanate (FITC)conjugate anti-rabbit immunoglobulin (1:200, 

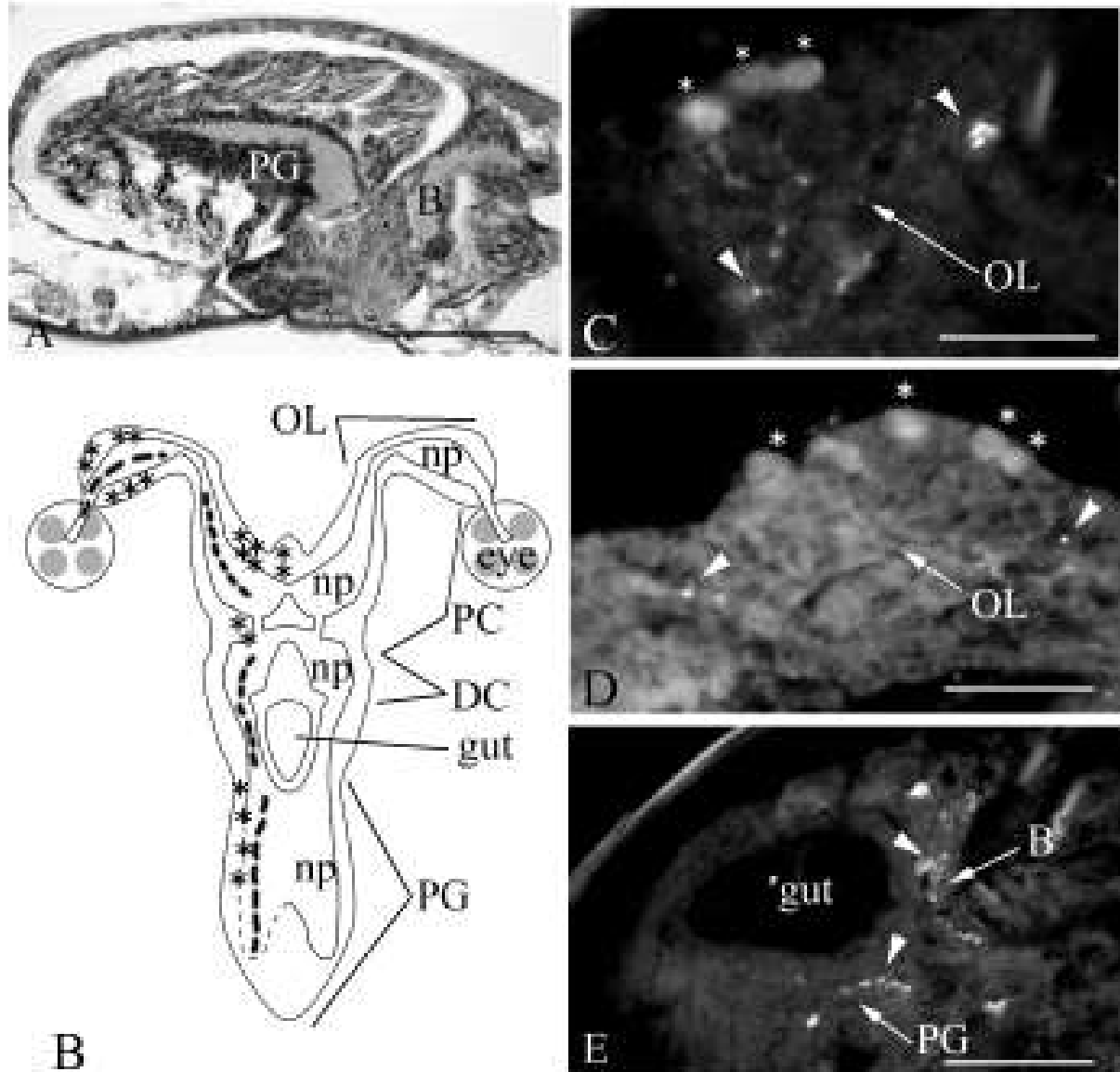
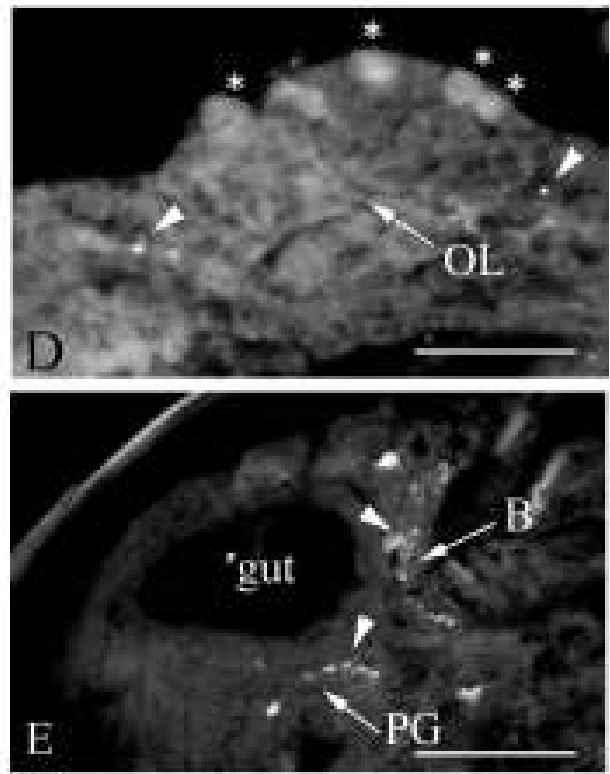

Figure 1. A Sagittal section of a barnacle cyprid. Haematoxylin and eosin. $B=$ brain, $P G=$ posterior ganglion. Scale bar $=100$ $\mu \mathrm{m}$.

B. Schematic drawing of the cyprid nervous system, modified from Harrison and Sandeman (1999). The drawing is based on the finding from both colchicine and non colchicine treated animals. The asterisks show the localization of the immunoreactive neuronal cell bodies, while the dashed line the course of immunoreactive nerve fibers. $O L$ $=$ optic lobe, $\mathrm{np}=$ neuropil, $\mathrm{PC}=$ protocerebrum, $\mathrm{DC}=$ deutocerebrum, $\mathbf{P G}=$ posterior ganglion.

C-E. Colchicine treated cyprid, immunofluorescence (IF).

Arrowhead $=$ immunoreactive nerve fiber, asterisk= immunoreactive neuronal cell body.

C. Sagittal section of the optic lobe showing three ventral immunoreactive neuron cell bodies. Scale bar $=\mathbf{3 0} \mu \mathrm{m}$.

D. Transversal section of the optic lobe. Two clusters of neurons in the dorsal region can be observed. Scale bar $=\mathbf{3 0} \mu \mathrm{m}$. E. Sagittal section. Immunoreactive nerve fibers characterized by large varicosities were found in the neuropil area of the brain (B) and posterior ganglion (PG). Scale bar $=65 \mu \mathrm{m}$
DAK0, DK), or with a goat Alexa-488-conjugate anti-rabbit immunoglobulin (1:800, Molecular Probes, NL) as secondary antiserum. The DAPI nuclear counter-stain (diamino-4',6-diamidino-2phenylindole-dihydrochloride-hydrate) (Sigma, USA) was used for visualizing the localization of the immunoreactivity in the neuronal compartments. The fluorescence was observed on a BX 50 Olympus epifluorescence microscope, with the filter for DAPI, FITC and tetramethyl rhodamine isothiocyanate (TRITC) fluorochromes, equipped with an Olympus Camedia 4040 digital photographic camera. Specificity controls, such as the substitution of the serotonin antiserum with a non-immune serum and the use of the preabsorbed serotonin antiserum with its antigen ( $10 \mu \mathrm{g} / \mathrm{mL}$ of the diluted primary antiserum), were performed. About 100 cyprids and 60 colchicine treated cyprids were observed. Cyprid histomorphology was studied through haematoxylin and eosin staining.

\section{Results}

The CNS of the barnacle cyprid consists of a brain (B) and a posterior ganglion (PG) (Harrison and Sandeman, 1999), connected to each other by paired circumesophageal connectives (Figure 1A). The CNS is composed of a centrally positioned neuropil (np) surrounded by cortical neuronal cell bodies (Figure 1B). The brain can be subdivided in protocerebrum (PC) and deutocerebrum (DC). No signs of tritocerebrum can be observed. The protocerebrum presents three regions, two optic lobes $(\mathrm{OL})$ that are anterolateral extensions of the brain, one dorsofrontal region and one median protocerebral region. The deutocerebrum shows the median deutocerebral neuropil and is connected to the antennules via antennular nerves. The posterior ganglion ( $P G)$, with the ventral cord, is composed of several fused parts: the anterior portion, deriving from three sub-esophageal neuromeres, and the 

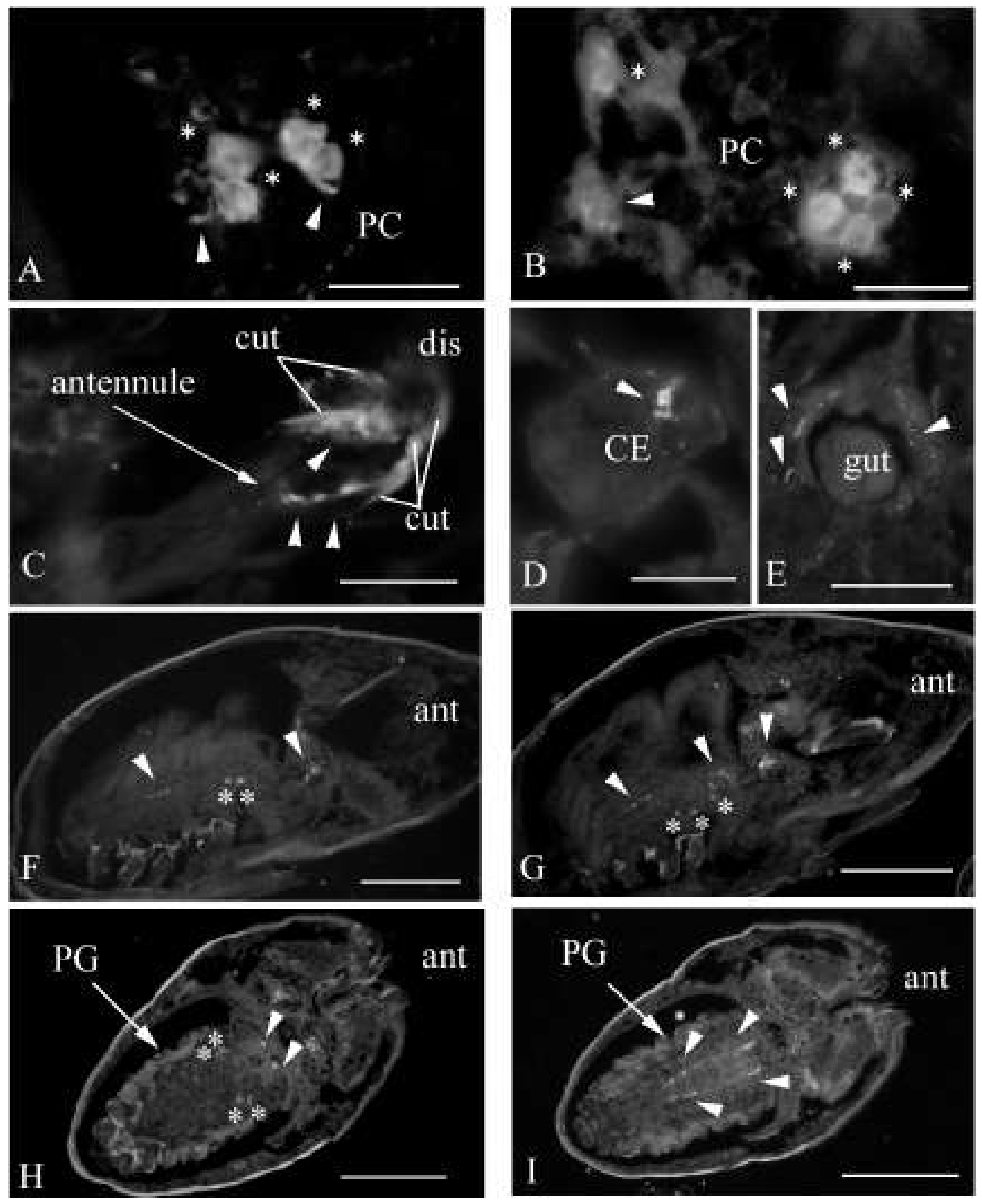

Figure 2. A-B. Colchicine treated cyprid, immunofluorescence (IF). Arrowhead = immunoreactive nerve fiber, asterisk $=$ immunoreactive neuronal cell body. A. Transversal section through the frontal hemi-protocerebral region (PC) showing the two contralateral pair of roundish serotonergic neurons. Scale bar $=25 \mu \mathrm{m}$. B. Sagittal section through the median PC showing four adjacent neurons. Scale bar $=\mathbf{2 5} \mu \mathrm{m}$. C-E Non-colchicine treated cyprid. IF. Arrowhead = immunoreactive nerve fiber; asterisk = immunoreactive neuronal cell body; dis = distal. $C$. Two thin immunoreactive varicose fibers innervate the distal end of the antennula. The cuticle (cut) shows non specific fluorescence. Scale bar $=\mathbf{5 0} \mu \mathrm{m}$. D. Immunoreactive nerve terminals in the optic nerve and in the compound eye (CE). Scale bar $=20 \mu \mathrm{m}$. E. Transversal section showing the gut wall surrounded by immunoreactive nerve fibers. Scale bar $=35 \mu \mathrm{m}$. F-I. Colchicine treated cyprid. IF. Arrowhead = immunoreactive nerve fiber; asterisk = immunoreactive neuronal cell body; ant $=$ anterior cyprid region. F-G. Serial sagittal sections of the PG. F. One anterior and one posterior immunoreactive neuronal cell bodies and nerves fibres in the sub-esophageal hemiganglion are shown. Scale bar $=\mathbf{1 0 0} \mu \mathrm{m}$. G. The posterior immunoreactive neuron and nerves fibres in the sub-esophageal hemiganglion and one anterior and one posterior immunoreactive neurons in the first thoracic subdivision are shown. Scale bar $=100 \mu \mathrm{m}$. H. Frontal section showing the two contralateral pairs of neurons and nerves fibres in the sub-esophageal hemiganglion. Scale bar $=125 \mu \mathrm{m}$. I. Frontal section. Two strongly immunoreactive longitudinal ventral cords were present along the medial line of the posterior ganglion. Scale bar $=125 \mu \mathrm{m}$. 
posterior portion deriving from the remaining six subdivisions, corresponding to the thoracic ganglia. Cyprid histomorphology and the segmentation of central nervous system were extensively described by Harrison and Sandeman (1999).

\section{Immunohistochemistry}

Serotonin-like immunoreactivity was localized throughout the nervous system of $B$. amphitrite cyprids. Its distribution and the intensity of the immunoreaction are related to the colchicine treatment. Using the anesthetic as pre-fixing agent only, the immunoreactivity was mainly detected in thin nerve fibers located both in the CNS and peripheral organs; the neuronal cell bodies were faintly immunoreactive.

The pre-anesthesia colchicine treatment intensified neuronal cell bodies immunoreactivity and modified the appearance of the neuropil nerve fibers which were characterized by large and strongly immunoreactive varicosities. In this condition, no immunoreactivity was detected in the peripheral organs.

All specificity controls, both in colchicine or in the non-colchicine treated cyprids, gave negative results. The distribution of serotonin immunoreactive neurons and nerve fibres in the cyprid nervous system is indicated in Figure $1 \mathrm{~B}$. The drawing is based on the findings from both colchicine and non colchicine treated animals.

In the colchicine treated specimens, at least seven immunoreactive neurons were detected in each optic lobe: a cluster of three strictly adjacent neurons were localized in the ventral apical area, near the eye (Figure $1 \mathrm{C}$ ), as well as two clusters, of one pair each, in the dorsal region (Figure 1D). A few immunoreactive nerve fibers, running longitudinally towards the median protocerebral neuropil area and a dense meshwork of immunoreactive fibers were also seen traveling along the median protocerebral neuropil to the deutocerebral neuropil area (Figure 1E). In the dorso-frontal protocerebral region, two contralateral pairs of roundish serotonergic neurons were detected; their arcuate processes extend to the neuropil area (Figure 2A). In the median protocerebral region there were two contralateral clusters of immunoreactive neurons: two strictly adjacent neurons were present in the former while four neurons could be found in the latter (Figure 2B). Two contralateral clusters of immunoreactive neurons were present in the dorsal portion of the deutocerebrum, near the exit of the antennular nerve; they probably send varicose immunoreactive nerve fibers along the whole antennule, up to the distal end, as can be seen in the non-colchicine treated specimens (Figure 2C). Furthermore, in the non-colchicine treated specimens, immunoreactive nerve terminals were also present in the optic nerve and compound eye (Figure 2D). Bundles of strongly immunoreactive fibers moved from the brain to the circumesophageal connectives that surround the gut (Figure 2E).

In the posterior ganglion, only four contralateral pairs of immunoreactive neurons were observed: one anterior and one posterior immunoreactive neuron in the hemiganglion of the sub-esophageal division and in the first thoracic neuromere (Figsure 2 F-G-H). The other ganglia of the thoracic subdivisions did not present serotonin immunoreactive neurons. Furthermore, two strongly immunoreactive medial longitudinal tracts were observed (Figure $2 \mathrm{I}$ ). In the non colchicines treated cyprids, serotonin immunoreactive nerve fibres were also observed along the thoracic limbs (not shown).

\section{Discussion}

The present results provide the first anatomical description of serotonin-like immunoreactivity in the nervous system of $B$. amphitrite cyprids. Its presence was previously determined in cypris larvae by HPLC (Yamamoto et al., 1999), and later confirmed by Okazaki and Shizuri (2001) with the identification of the aromatic L-amino acid decarboxylase $(A A D C)$ gene. In $B$. amphitrite cyprids, both immunoreactive neuronal cell bodies and nerve terminals were observed. The faint immunolabelling of the neuronal cell bodies was overcome by the use of colchicine as pre-fixing agent. Colchicine destroys microtubule organization and interrupts axonic transport; as a consequence, the neurosecretion is accumulated in the cell body or in the proximal portion of its cytoplasmic extension, located in the neuropil area. The distribution of serotonin immunoreactive neurons in the cyprid differed from that observed in the adult barnacle (Callaway and Stuart, 1999); in particular, in the brain region of adult barnacle, at least 14 serotonin immunoreactive neurons were found in each hemiganglion. Although no data are available for the adult of $B$. 
amphitrite, in the adult brain of $B$. nubilus (Callaway and Stuart, 1999), three pairs of small serotonin immunoreactive neurons have been found, and they probably correspond to one of the immunoreactive neurons of the median protocerebral dorsal region and to the immunoreactive neurons near the antennular nerve exit. This difference can be related to the presence of a complex system of sensory organs, such as the compound lateral eyes and the antennules in the cyprid head, which are reduced or lacking in the adult. The small number of serotonergic neurons identified in the adult barnacle brain seems to be related to median ocellus; an interaction of serotonergic neurons with histaminergic neurons in the optic pathways has been previously suggested by Callaway and Stuart (1999). The serotonin immunoreactive neurons in the cyprid, particularly numerous in the optic lobe protocerebral and deuterocebral regions, may be involved in the visual pathways as well as in the control of the antennule movements (Schmidt and Ache, 1996; Cate and Derby, 2001; Lagersson and Hoeg, 2002). Serotonergic neurons localized in the brain are probably responsible for the innervation of the chemoreceptive distal antennular portion, as well as of the compound eyes. In this way, visual information through serotoninergic neurotransmition might affect substrate recognition. This hypothesis is supported by previous experiments which demonstrated that serotonin can influence settlement processes (Yamamoto et al. 1996; Rittschof et al. 2003).

Fewer serotonin immunoreactive neurons were instead found in the cyprid posterior ganglion in comparison to the adult counterpart (Balanus cariosus) where at least fourteen immunoreactive neurons were found (Callaway and Stuart, 1999). The first two pairs of immunoreactive neurons in the cyprid posterior ganglion may correspond to the anteriormost pairs of neurons in the posterior ganglion of adult acorn barnacle, innervating the anterior part of the body. The two other pairs of neurons in the first thoracic segment may correspond to those still present in the adult barnacle. At present, there are no data on the role played by these neurons. As already stated by Callaway and Stuart (1999), it is very improbable that serotonin could act as a neurotransmitter on cirral muscular structures, since only three out of six cirral nerve roots in the adult and only one out six in the cyprid show serotonin immunolabelling. Nevertheless, the pat- terns of serotonergic neurons in the first thoracic ganglia of the cyprid, costituted by an anterior and a posterior bilateral pair of neurons, is similar to those observed in other Crustacea as described by Harzsch and Waloszek (2000). Since there are numerous species differences among barnacles, a better comparison on the serotonergic system could be made by studying the adult counterpart of the same species $B$. amphitrite.

\section{Acknowledgements}

This work was supported by MIUR funds, Project MEMOBIOMAR (law 248), and by the project funded by the European Community: SENS-PESTI QLK4-CT-2002-02264.

The experiments comply with the current European laws of bioethics.

\section{References}

Azmitia EC. Modern views on an ancient chemical: Serotonin effects on cell proliferation, maturation, and apoptosis. Brain Res Bull 2001; 56:413-24.

Battelle BA, Calman BG, Hart MK. Cellular distributions and functions of histamine, octopamine and serotonin in the peripheral visual system, brain, and circumesophageal ring of the horseshoe crab Limulus polyphemus. Microsc Res Tech 1999; 44:70-80.

Beltz BS, Kravitz EA. Mapping of serotonin-like immunoreactivity in the lobster nervous system. J Neurosci 1983; 3:585-602.

Callaway JC, Stuart AE. The distribution of histamine and serotonin in the barnacle's nervous system. Microsc Res Tech 1999; 44:94-104.

Cate HS, Derby CD. Morphology and distribution of setae on the antennules of the Caribbean spiny lobster Palinurus argus reveal new types of bimodal chemo-mechanosensilla. Cell Tissue Res 2001; 304: 439-54.

Christie A0, Dalley R. Barnacle fouling and its prevention. In: Southward AJ, ed. Barnacle Biology. Balkema: Rotterdam. 1987; pp. 419-33.

Crisp DJ. Overview of research on marine invertebrate larvae, 19401980. In: Costlow JD and Tipper RC, editors. Marine Biodeterioration: an Interdisciplinary Study: 103-126. Annapolis, Maryland, Naval Institute Press. 1984; pp. 103-26.

Faimali M, Falugi C, Gallus L, Piazza V, and Tagliafierro G. Involvement of acetylcholine in settlement process of Balanus amphitrite. Biofouling 2003, 19:213-20.

Fuji K, Takeda N. Phylogenetic detection of serotonin immunoreactive cells in the central nervous system of invertebrates. Comp Biochem Physiol 1988; 89:233-39.

Gallus L, Diaspro A, Beltrame F, Fato M, Tagliafierro G. Three dimensional computer aided reconstruction of FMRF-amide immunopositive neuron distribution in the ventral ganglion of the barnacle Balanus amphitrite (Cirripedia, Crustacea). Eur J Histochem 2001, 45: 95-104.

Gwilliam GF, Cole ES. The morphology of the central nervous system of the barnacle Semiballanus carosus (Pallas). J Morphol 1979, 159:297-310.

Gwilliam GF. Neurobiology of barnacles. In: Southward AJ (ed), Barnacle Biology. Balkema, Rotterdam, 1987 pp. 191-211.

Harris-Warrick RM, Kravitz EA. Cellular mechanisms for modulation of posture by octopamine and serotonin in the lobster. J Neurosci 1984; 4:1976-93.

Harrison PJH, Sandeman DC. Morphology of the nervous system of the barnacle cyprids larva (Balanus amphitrite) revealed by light and electron microscopy. Biol Bull 1999; 197:144-58.

Harzsch S, Waloszek D. Serotonin-immunoreactive neurons in the ven- 
tral nerve cord of Crustacea: a character to study aspects of arthropod phylogeny. Arthropod Struct. Dev. 2000, 29: 307-322.

Kon-Ya K, Endo M. Catecholamines as settlement inducers of barnacle larvae. J Mar Biotechnol 1995; 52:79-81.

Langersson NC, Hoeg JT. Settlement behavior and antennulary biomechanics in cypris larvae of Balanus amphitrite (Crustacea: Thecostraca: Cirripedia) Mar Biol. 2002, 141: 513-526.

Listerman LR, Deskins J, Bradacs H, Cooper RL. Heart rate within male crayfish: social interactions and effects of 5-HT. Comparative Biochemistry and Physiology - Part A: Molecular \& Integrative Physiology 2000; 125: 251-63.

Moiseiwitsch JRD, Lauder JM. Serotonin regulates mouse cranial crest migration. Proc Nat Acad Sci USA 1995; 92: 7182-86.

Newman WA. Evolution of cirripedes and theirs major group. In: Southward AJ, editor. Barnacle Biology. Balkema: Rotterdam 1987; pp. 3-42.

Okano K, Shimizu K, Glenn SC, Fusetani N. Visualization of cement exocytosis in the cement gland of the barnacle Megabalanus rosa. $J$ Exp Biol 1996; 199:2131-37.

Okazaki $Y$, Shizuri $Y$. Identification of the aromatic L-amino acid decarboxylase (AADC) gene and its expression in the attachment and metamorphosis of the barnacle, Balanus amphitrite. Develop Growth Differ 2001; 43:33-41.

Rittschof D, Clare AS, Gerhart DJ, Sister Avelin Mary, Bonaventura J. Barnacle in vitro assays for biologically active substance: toxicity and settlement inhibition assay using mass cultured Balanus amphitrite amphitrite Darwin. Biofouling 1992; 6:115-22.

Ritthschof D, Lai CH, Kok LM, Teo SL. Pharmaceuticals as antifoulants: concept and principles. Biofouling 2003; 19:207-12.

Schmidt M, Ache BW. Processing of antennular input in the brain of the spiny lobster, Palinurus argus. 1. Non-olfactory chemosensory and mechanosensory pathway of the lateral and median antennular neuropils. J Comp Physiol A 1996; 178: 579-604.

Strathmann RR. Larval feeding in AC Geise, JS Pearse and VB Pearse (eds.) Reproduction of marine invertebrates, vol.9. Palo Alto, CA:
Blackwell Scientific Publications, and Pacific Grove, CA: Boxwood Press, 1987; pp. 465-50.

Stuart AE, Mekeel HE, Kempter E. Uptake of the neurotransmitter histamine into the eyes of larvae of the barnacle (Balanus amphitrite) Biol. Bull. 2002, 202:53-60.

Tagliafierro G, Rossi GG, Crosa C. Neural FMRFamide-like peptide in Balanus amphitrite. Bas Appl Histoch 1989; 33:98.

Walker GA. A study of the cement apparatus of the cyprids larva of the barnacle, Balanus balanoides. Mar Biol 1971; 9:205-12.

Walker GA, Yule AB, Nott JA. Structure and function in balanomorph larva. In: Southward AJ, editor. Barnacle Biology. Balkema: Rotterdam 1987; pp.307-28.

Walker GA Cirripedia. In: Harrison FW and Humes AG, editors. Crustaceans. New York: Wiley-Liss. 1992; pp. 249:311.

Webster SG (1998) Peptidergic neurons in barnacles: an immunohistochemical study using antisera raised against crustacean neuropeptides. Biol. Bull. 195: 282-289.

Yamamoto H, Tachibana A, Kawaii S, Matsumura K, Fusetani N. Serotonin involvement in larval settlement of the barnacle, Balanus amphitrite. J Exp Zool 1996; 275:339-45.

Yamamoto H, Fujimiya M, Shirai Y, Nakashita M, Oyasu M, Saito N. Immunohistochemical localization of serotonin transporter in normal and colchicine treated rat brain. Neurosc Res 1998; 32:305-12.

Yamamoto H, Shimizu K, Tachinaba A, Fusetani N. Roles of dopamine and serotonin in larval attachment of the barnacle, Balanus amphitrite. J Exp Zool 1999; 284:746-58.

Yeh $\mathrm{S}$, Musolf BE, Edwards DH. Neuronal adaptations to changes in the social dominance status of crayfish. Neurosci 1997; 17:697708.

Yule AB, Walker G. Adhesion in barnacles. In: Southward AJ, editor. Barnacle Biology. Crustacean issues, 5. Balkema, Rotterdam. 1987; pp. 389-402. 
L. Gallus et al. 